\title{
Criminologie
}

\section{En hommage à Alice Parizeau}

\section{Jacqueline De Plaen}

Volume 24, numéro 1, 1991

Les droits des détenu-e-s

URI : https://id.erudit.org/iderudit/017298ar

DOI : https://doi.org/10.7202/017298ar

Aller au sommaire du numéro

Éditeur(s)

Les Presses de l'Université de Montréal

ISSN

0316-0041 (imprimé)

1492-1367 (numérique)

Découvrir la revue

Citer ce document

De Plaen, J. (1991). En hommage à Alice Parizeau. Criminologie, 24(1), 3-4.

https://doi.org/10.7202/017298ar

Ce document est protégé par la loi sur le droit d'auteur. L'utilisation des services d'Érudit (y compris la reproduction) est assujettie à sa politique d'utilisation que vous pouvez consulter en ligne.

https://apropos.erudit.org/fr/usagers/politique-dutilisation/
Cet article est diffusé et préservé par Érudit.

Érudit est un consortium interuniversitaire sans but lucratif composé de l’Université de Montréal, l'Université Laval et l'Université du Québec à Montréal. Il a pour mission la promotion et la valorisation de la recherche. https://www.erudit.org/fr/ 
Peu de personnes auront vécu aussi intensément qu'Alice PoznanskaParizeau. Née en Pologne en 1930, établie au Québec en 1955, à la fois journaliste, intervenante sociale, titulaire de recherche, essayiste et romancière, Mme Parizeau avait étudié en France à l'École des sciences politiques et à la faculté de droit de Paris. La carrière pour le moins polyvalente qui fut la sienne était le reflet du courage, de l'enthousiasme et du dynamisme de sa personnalité.

La criminologie fut l'une des facettes de ses activités. Elle devient secrétaire à la rédaction de Criminologie alors que la revue entrait dans sa huitième année. En 1975, avec l'assistance d'un comité de rédaction de trois membres, elle a assuré la publication du numéro annuel de près de deux cents pages et, deux ans plus tard, à son initiative, la revue devenait semestrielle. Jusqu'en 1982, elle administrera le périodique, en corrigera les épreuves, le fera connaître à l'étranger au cours de ses voyages. Elle y signera même près d'une douzaine d'articles, parfois rédigés la nuit sous la pression des dates de tombée, en remplacement d'un auteur ayant fait faux bond au dernier moment.

Sans détenir de formation particulière en criminologie, elle a pourtant participé à de nombreuses recherches au sein des équipes du Centre international de criminologie comparée de l'Université de Montréal. Le regard neuf et critique qu'elle apportait à tout problème social et l'intérêt qu'elle manifestait pour les questions les plus diverses l'ont entre autres dirigée vers l'étude comparative de la criminalité au Canada et dans les pays de l'Est, la déviance et le contrôle social dans les communautés inuit de Frobisher Bay, le rôle et le statut des juges en chef au Canada, le rapport présentenciel et les aspects théoriques de même que les applications concrètes de la déjudiciarisation.

Les mondes de l'édition et de l'écriture lui étaient chers. Elle disait souvent que l'écriture était le véhicule privilégié des idées et des changements sociaux. Quant à l'édition, elle avait ses vues bien à elle sur les politiques à suivre dans ce domaine. À son avis, le livre devait être accessible à tous, se vendre partout et au coût le plus bas possible. Aussi fut-elle heureuse de voir un de ses romans publié en feuilleton dans La Presse et de constater par la suite que les œuvres québécoises prenaient progressivement leur place dans le quotidien.

* Centre international de criminologie comparée, Université de Montréal, Case postale 6128, Succ. «A», Montréal (Québec) H3C 3J7. 
Femme engagée, militante des droits de la personne, Mme Parizeau s'est intéressée particulièrement au sort réservé aux enfants, qui représentaient pour elle une valeur sacrée. Ses rapports de recherche et ses livres y consacrent plusieurs chapitres parmi les meilleurs.

Ainsi, dans L'Adolescent et la société (1972), Ces jeunes qui nous font peur (1972), L'Envers de l'enfance (1976) et Protection de l'enfance : échec? (1979), elle expose ses préoccupations les plus vives à l'égard des enfants négligés et soumet aux lecteurs des solutions concrètes pour remédier à leur situation. Ses proches ont été témoins de ses multiples interventions personnelles auprès des jeunes parmi les plus démunis et de leurs parents.

À travers ses travaux sur les institutions, dont le rapport pour la Commission d'enquête Prévost sur l'administration de la justice pénale au Québec (1970), on décèle une préoccupation constante pour la personne. Cet intérêt se manifeste aussi bien dans son œuvre littéraire, qui prend peu à peu une forme épique, qu'à travers ses essais et même ses recherches criminologiques. Cette dualité entre l'institution sociale et l'individu constitue l'essentiel du dynamisme propre à son œuvre. Si la famille, la maison, l'université, le pays et la société sont, pour elle, autant de lieux de vie, autant d'occasions d'agir, de combattre, d'écrire, la personne et ses droits fondamentaux demeurent le point de convergence et l'aboutissement de sa démarche comme femme et comme écrivaine.

La société a reconnu les mérites d'Alice Parizeau à plusieurs reprises. Notamment, on lui a remis la Croix de Fer, à la Libération de 1945, pour ses activités dans la résistance. Son roman Les lilas fleurissent à Varsovie lui a valu le Prix européen des écrivains de langue française, en 1982. On la nomma membre de l'Ordre du Canada, en 1987. Et, en novembre 1990, la Société Saint-Jean-Baptiste vient de lui accorder, à titre posthume, la médaille d'argent Bene Merenti de Patria pour services exceptionnels à la patrie, aux côtés d'illustres prédécesseurs comme Marie Gérin-Lajoie, Wilfrid Pelletier et le docteur Armand Frappier.

Son sens de l'humour, sa facilité à communiquer, son goût de la lutte et surtout sa sincérité jamais démentie ont dicté à Jean Éthier-Blais le portrait suivant:

Alice Parizeau se tenait debout à côté de la liberté (...) elle avait la démocratie chevillée au corps.

(Le Devoir, $1^{\text {er }}$ octobre 1990.)

Voilà l'héritage que nous lui serons à jamais reconnaissants d'avoir su nous transmettre. 